\title{
Eclampsia: maternal and perinatal outcomes in a tertiary care centre
}

\author{
Sunita Mor*, Daya Sirohiwal, Reetu Hooda
}

Department of Obstetrics \& Gynaecology, Pt. B.D. Sharma PGIMS, Rohtak, Haryana, India

Received: 08 March 2015

Accepted: 19 April 2015

\section{*Correspondence:}

Dr. Sunita Mor,

E-mail: drsunita.mor@gmail.com

Copyright: (c) the author(s), publisher and licensee Medip Academy. This is an open-access article distributed under the terms of the Creative Commons Attribution Non-Commercial License, which permits unrestricted non-commercial use, distribution, and reproduction in any medium, provided the original work is properly cited.

\begin{abstract}
Background: Eclampsia is a life threatening emergency that continues to be a major cause of maternal and perinatal mortality. The purpose of our study was to analyse the trend of eclampsia in a tertiary care teaching institute and to find out maternal and perinatal outcomes of eclampsia.

Methods: A prospective study was undertaken in a tertiary care teaching institute over a period of one year. Patients of eclampsia were followed up with regard to the management and maternal and fetal morbidity and mortality. Data was recorded and analysed. Maternal outcome was measured in terms of mode of delivery, complications like pulmonary oedema, haematological disorders, renal failure, cerebral haemorrhage and maternal death. Perinatal outcome was noted in terms of prematurity, admission to NICU and neonatal deaths.

Results: The incidence of antepartum eclampsia was $1.08 \%$. High risk associated factors were primigravida, low maternal age (21-25 years), low socio-economic status, illiteracy and inadequate antenatal care. Caesarean section was the mode of delivery in 26 cases $(52 \%)$. There was $4 \%$ maternal mortality \& attributed to aspiration pneumonia and pulmonary oedema. Maternal Complications were observed in $38 \%$ cases, most common was status eclampticus (12\%) followed by HELLP syndrome (6\%). Prematurity complicated $48 \%$ pregnancies and SGA in $14 \%$. Fourteen neonates were admitted in NICU and there were 4 neonatal deaths.

Conclusions: Eclampsia is one of the important causes of maternal and perinatal morbidity and mortality due to lack of proper antenatal care, low socio-economic status and lack of education. Early attention and intensive management are essential for improving the maternal and fetal outcomes. Unless the social and educational status of women is uplifted and obstetric care is brought to the doorstep, no miracle can be expected.
\end{abstract}

Keywords: Eclampsia, Maternal outcome, Perinatal outcome

\section{INTRODUCTION}

The term "eclampsia" is derived from a Greek word meaning "like a flash of lightening". Alexander Hamilton (1781) described eclampsia as a disease which is always attended with the utmost hazard and frequently kills the woman like a fit of apoplexy. Unfortunately, few women develop dreaded complications that may result in adverse obstetric outcomes.

Eclampsia is a life threatening emergency that continues to be a major cause of maternal and perinatal mortality worldwide. Maternal mortality varies widely at different places with almost identical management indicating that there may be an important differences in socio-economic condition of a nation and the quality of obstetric care.

In UK incidence of eclampsia is $4.9 / 10000$ and in USA it is $4.3 / 10000$ deliveries. ${ }^{1}$ Unfortunately, eclampsia still complicates much larger number of pregnancies in world. In, India its incidence is reported to be 220/10000 deliveries. $^{2}$ It is estimated that about $7 \%$ of maternal mortality is associated with hypertensive disorders of pregnancy, particularly eclampsia. ${ }^{3}$ 
With better antenatal care, early recognition and hospital treatment of severe preeclampsia patients, the incidence of eclampsia can be decreased. But there are a minority of patients in whom eclampsia comes like a "Bolt from the blue". For these unfortunate and ignorant patients, we can offer service by reducing both maternal and perinatal mortality due to eclampsia by timely intervention and management.

We conducted this study to determine the trend of eclampsia in our tertiary care institute, associated complications and effect on maternal and fetal outcomes.

\section{METHODS}

The present prospective study was conducted on women with antepartum eclampsia, admitted and managed in maternity unit of Pt. B.D. Sharma PGIMS, Rohtak over a one year period (Jan 2013 to Dec 2013). Women with known history of epilepsy, head injury, meningitis, cerebral malaria were excluded from the present study. After a written informed consent, detailed history was taken and general physical and obstetric examination was carried out. Complete hemogram with platelet count, blood group, HIV, HBsAg, STS, coagulation profile, liver function test, kidney function test, complete urine examination and fundus examination were done. Blood pressure was recorded in right arm in lying down position with arm at level of heart using a mercury sphygmomanometer. Korotkoff sound $\mathrm{V}$ was used to measure diastolic pressure.

All patients received magnesium sulphate $\left(\mathrm{MgSO}_{4}\right)$ except those with contraindications (absent knee jerk, respiratory depression, urine output $<30 \quad \mathrm{ml} /$ hour) received phenytoin. Patients received $\mathrm{MgSO}_{4}$ as per Pritchard regime (Loading dose $4 \mathrm{gm}$ of magnesium sulphate as a $20 \%$ solution intravenously at a rate not exceeding $1 \mathrm{gm} / \mathrm{min}$, accompanied by $10 \mathrm{gm}$ of magnesium sulphate solution, one half (5 gm) injected deep intramuscular in upper outer quadrant of each buttock with a 3 inch long 20 gauge needle. This was followed by maintenance dose: Every four hour, thereafter given $5 \mathrm{gm}$ of $50 \%$ solution of magnesium sulphate injected deep i.m. in upper outer quadrant of alternate buttock. Magnesium sulphate was discontinued 24 hours after delivery.

Phenytoin was given as $600 \mathrm{mg}$ in $300 \mathrm{ml}$ normal saline intravenously slowly over 30 minutes followed by 300 $\mathrm{mg}$ in $200 \mathrm{ml}$ normal saline slowly over 30 minutes followed by a maintenance dose of $100 \mathrm{mg}$ in $100 \mathrm{ml}$ normal saline intravenously 8 hourly.

Patients were scheduled for vaginal delivery unless there were indications for caesarean section (e.g. status eclampticus, contracted pelvis, foetal distress). Patients in labour were monitored as per partogram. Patient with poor Bishop score were induced with vaginal $\mathrm{PGE}_{1}$ (misoprostol) $25 \mu \mathrm{g}$ or $\mathrm{PGE}_{2}$ (Dinoprostone) gel $0.5 \mathrm{mg}$ and reassessed after 4 hours. If no improvement was found then patients were considered for caesarean section. If Bishop score was favourable then augmentation of labour was done with oxytocin and amniotomy was performed. The duration of labour, mode of delivery and maternal and perinatal complications, if any were recorded.

\section{Statistical analysis}

At the end of the study, the data was collected and analysed by using Chi-square test/Fischer exact test. A P value of $<0.05$ was considered as significant.

\section{RESULTS}

In our institute, incidence of antepartum eclampsia was $1.08 \%$. Majority of eclamptic women $(82 \%)$ belonged to 21-25 years age group. $18 \%$ of the women were illiterate and $36 \%$ had primary level of education. Only $4 \%$ of the eclamptic women were graduates or postgraduates. Maximum eclamptic women were housewives $(92 \%$ of the study population). A very large number of women (80\%) belonged to lower socioeconomic class. Threequarters of the women who developed eclampsia were primigravidas (74\%), 14\% were second gravida and the remaining $12 \%$ were third gravida or more. Mean duration of marriage was $2.72 \pm 3.55$ years and mean parity was $0.3 \pm 0.7$. The mean duration of pregnancy was $8.29 \pm 0.94$ months and $24 \%$ cases had a gestational age of less than 7 months. $98 \%$ women presenting as eclampsia were unbooked and reported as an emergency case, whereas only one patient was a booked case with regular antenatal visits. Table 1 shows the significance of antenatal care.

Table 1: Maternal outcome in relation to antenatal care.

\begin{tabular}{|llll|}
\hline ANC & $\begin{array}{l}\text { No. of } \\
\text { patients }\end{array}$ & Deaths & Discharged \\
\hline Emergency & $49(98 \%)$ & $2(4 \%)$ & $47(94 \%)$ \\
\hline Booked & $1(2 \%)$ & 0 & $1(2 \%)$ \\
\hline $\begin{array}{l}\text { Statistical } \\
\text { significance }\end{array}$ & & $\begin{array}{l}\chi^{2}=5.62 ; \mathrm{P}=0.01 \\
\text { Significant }\end{array}$ \\
\hline
\end{tabular}

The most common presenting symptom in eclampsia patients was headache $(60 \%)$, followed by pedal edema (22\%), blurring vision (10\%) and epigastric discomfort $(8 \%)$. All women were initially given magnesium sulphate, but later $5 \%$ had to be switched to phenytoin due $\mathrm{MgSO}_{4}$ toxicity. Three women needed an additional therapeutic agent (Leviracitam or Phenobarbitone) to control the convulsions.

Twenty four women (48\%) were delivered vaginally whereas $52 \%$ required caesarean section (Table 2). Out of the patients delivered vaginally, $7(14 \%)$ required instrumental delivery (vacuum or forceps). The indications of caesarean sections are shown in Table 3. 
Table 2: Maternal outcome in relation to mode of delivery.

\begin{tabular}{|ll|} 
Mode of delivery & $\begin{array}{l}\text { No. of } \\
\text { patients } \\
(\mathbf{n}=50)\end{array}$ \\
\hline LSCS & $26(52 \%)$ \\
\hline Vaginal delivery & $24(48 \%)$ \\
\hline PTVD & $13(26 \%)$ \\
\hline FTVD & $4(8 \%)$ \\
\hline Instrumental & $7(14 \%)$ \\
\hline
\end{tabular}

Table 3: Indications of caesarean sections in eclampsia patients.

\begin{tabular}{|lll|} 
Indications & $\begin{array}{l}\text { No. of } \\
\text { patients } \\
(\mathbf{n = 2 6})\end{array}$ & $\begin{array}{l}\text { Percentage } \\
(\%)\end{array}$ \\
\hline Fetal distress & 11 & 42.4 \\
\hline Malpresentation & 02 & 7.7 \\
\hline Status eclampticus & 04 & 15.4 \\
\hline Obstructed labour & 01 & 3.8 \\
\hline Cephalopelvic disproportion & 01 & 3.8 \\
\hline Poor Bishop score & 07 & 26.9 \\
\hline
\end{tabular}

Table 4: Maternal outcome in relation to complications.

\begin{tabular}{|llll|}
\hline Complications & $\begin{array}{l}\text { No. of } \\
\text { patients }\end{array}$ & Deaths & Discharged \\
\hline Status eclampticus & $6(12 \%)$ & 0 & 6 \\
\hline Atonic PPH & $1(2 \%)$ & 0 & $1(2 \%)$ \\
\hline $\begin{array}{l}\text { Abruptio placenta } \\
\text { with DIC with } \\
\text { pulmonary edema }\end{array}$ & $1(2 \%)$ & $1(2 \%)$ & 0 \\
\hline ARF & $2(4 \%)$ & 0 & $2(4 \%)$ \\
\hline Aspiration pneumonia & $1(2 \%)$ & $1(2 \%)$ & 0 \\
\hline DIC & $2(4 \%)$ & 0 & $2(4 \%)$ \\
\hline $\begin{array}{l}\text { Cerebral venous } \\
\text { thrombosis }\end{array}$ & $1(2 \%)$ & 0 & $1(2 \%)$ \\
\hline HELLP & $3(6 \%)$ & 0 & $3(6 \%)$ \\
\hline Postpartum psychosis & $1(2 \%)$ & 0 & $1(2 \%)$ \\
\hline $\begin{array}{l}\text { Post. reversible } \\
\text { encephalopathy } \\
\text { syndrome }\end{array}$ & $1(2 \%)$ & 0 & $1(2 \%)$ \\
\hline No complications & $31(62 \%)$ & 0 & $31(62 \%)$ \\
\hline $\begin{array}{l}\text { Statistical } \\
\text { significance }\end{array}$ & & $\chi^{2}=33.10 ; \mathrm{P}=0.0001$ \\
\hline
\end{tabular}

Table 4 shows the maternal outcomes with reference to complications occurring in the study population. $38 \%$ of the women developed various complications. Status eclampticus was most common complication followed by hematological complications 10\% (HELLP 6\% and DIC $4 \%$ ). Out of these 2 women expired due to pulmonary oedema and aspiration pneumonia.12\% of the women required transfer to I.C.U. for ventillatory support, whereas the rest were managed in the high risk room of the labour ward. The overall mortality in eclampsia was $4 \%$ and both these deaths occurred in women who were unbooked patients. There was a statistically significant difference $(\mathrm{P}=0.0001)$ when patients discharged in healthy state were compared with maternal deaths due to eclampsia. The mean duration of hospital stay was $9 \pm$ 5.48 days.

The perinatal outcomes are depicted in Table 5. There were $48 \%$ preterm gestations. The mean baby weight was $2.00 \pm 0.73 \mathrm{~kg}$. Fourteen newborns were admitted in neonatal intensive care unit (NICU). Out of these, there were 4 neonatal deaths ( 1 term and 3 preterm births). Prematurity was the main cause of neonatal deaths (75\%). Among all eclampsia admissions, 20\% women had an intrauterine fetal death (IUFD). All these were preterm gestations and 7 fetuses weighed less than 1 kilogram.

Table 5: Perinatal outcome.

\begin{tabular}{|c|c|}
\hline & $\begin{array}{l}\text { No. of patients } \\
/ \text { Mean } \pm \text { SD }\end{array}$ \\
\hline \multicolumn{2}{|l|}{ Live } \\
\hline Yes & $40(80 \%)$ \\
\hline No & $10(20 \%)$ \\
\hline \multicolumn{2}{|l|}{ Gestation } \\
\hline Term & $26(52 \%)$ \\
\hline Preterm & $24(48 \%)$ \\
\hline Weight (kg) & $2.00 \pm 0.73$ \\
\hline IUGR (SGA) & $7(14 \%)$ \\
\hline Admitted to NICU & $14(28 \%)$ \\
\hline Discharged & $10(20 \%)$ \\
\hline Neonatal deaths & $4(8 \%)$ \\
\hline
\end{tabular}

Convulsion-to-delivery interval was less than 5 hours in $68 \%$ cases, and had better neonatal outcomes. Mean delivery interval was $4.16 \pm 3.70$ hours (Table 6 ).

Table 6: Convulsion-delivery interval in eclampsia patients.

\begin{tabular}{|lll|}
$\begin{array}{l}\text { Duration } \\
\text { (hours) }\end{array}$ & $\begin{array}{l}\text { No. of } \\
\text { patients }\end{array}$ & Final neonatal outcome \\
\hline$<1$ hour & $5(10 \%)$ & All Alive \& healthy \\
\hline $1-5$ hours & $29(58 \%)$ & All Alive \& healthy \\
\hline$>5-10$ hours & $11(22 \%)$ & $\begin{array}{l}5 \text { were IUFD, } 4 \text { neonatal } \\
\text { deaths, } 2 \text { alive \& healthy }\end{array}$ \\
\hline$>10$ hours & $5(10 \%)$ & All were IUFD \\
\hline
\end{tabular}

\section{DISCUSSION}

The incidence and mortality of eclampsia has fallen dramatically over the past decades. This is likely to be due to better antenatal care combined with improved social and economic conditions. However, in developing countries eclampsia still stands as one of the major complications of pregnancy. The incidence quoted from the leading centres of India varies from $0.18 \%$ to $4.6 \%$., 
The incidence of eclampsia in the present study was $1.08 \%$. The incidence of eclampsia in eastern India as quoted by Sunita et al. in a recent study was $3.2 \%$, which was higher than our study. ${ }^{6}$ This incidence of eclampsia is much higher than that of developed countries like the United Kingdom where eclampsia complicates only $0.05 \%$ of total deliveries. ${ }^{1}$

In the present study majority of eclamptic women $(82 \%)$ belonged to 21-25 years age group followed by $10 \%$ eclamptic women in 26-30 years. Sarkar M et al. reported eclampsia commonly occurs in younger age group of 1822 years. ${ }^{7}$ Yakasai et al. reported a mean age of 20.6 and SD of 5 years. $^{8}$ Kaur et al. also reported 20-25 years age group of $50 \%$ of their cases. ${ }^{9}$ Our results are comparable with these studies.

Majority of eclamptic women were educated upto less than primary level (54\%). Only 2 (4\%) eclamptic women had education of graduate/postgraduate level. Ndaboine et al. reported $75 \%$ cases educated upto primary level only. ${ }^{10}$ In the present study, maximum patients $(80 \%)$ belonged to low socio-economic strata. Khanum et al. reported $95 \%$ patients as illiterate and of low socio economic group. ${ }^{11}$ Sarkar M et al. studied 44 cases out of which 37 cases were of low socio economic status. ${ }^{7}$ Nobis PN reported low socio educational status of women and lack of essential obstetric care are fundamental determinants of maternal death. ${ }^{12}$

In the present study, a total of 37 women $(74 \%)$ were primigravidas and mean parity was $0.3 \pm 0.7$. Ndaboine et al reported that $60.5 \%$ as primigravida and $39.5 \%$ as multigravida. ${ }^{10}$ Sunita $\mathrm{TH}$ reported that majority of cases $79 \%$ were primigravida and $21 \%$ multigravida. ${ }^{6}$ Sheraz et al also reported a higher incidence of eclampsia in primigravidas $(69.1 \%) .{ }^{13}$ Analysis of occupational status revealed $92 \%$ housewives in our study. Ndaboine et al reported $40.8 \%$ housewives. ${ }^{10}$

The most common presenting symptom was headache (60\%), followed by pedal edema in $22 \%$ and $10 \%$ cases reported blurring of vision. Sibai BM reported headache in $50-75 \%$ of the patients, whereas visual changes were reported in $19-32 \%$ of the cases. ${ }^{14}$ Douglas and Redman reported 50 cases with headache, 19 cases with visual changes, 19 with epigastric pain/RUQ and 59 (any one of above) out of 325 cases studied. ${ }^{15}$ Chames et al. reported 79 cases with headache, 30 with visual changes, 12 with RUQ/epigastric pain out of 89 cases studied. ${ }^{16}$

In our study, we found eclamptic patients having systolic blood pressure $>160 \mathrm{mmHg}$ in $54 \%$ cases and diastolic blood pressure $>110 \mathrm{mmHg}$ in $56 \%$ patients. Suman $\mathrm{G}$ et al. reported $66 \%$ cases with severe hypertension $>160 / 110 .{ }^{17}$ Sunita TH also reported $68 \%$ cases as severe with blood pressure $>160 / 110 ; 20 \%$ mild with B.P. $<160 / 110$ and $12 \%$ with normal. ${ }^{6}$

A total of $38 \%$ complications occurred in the present study e.g. status eclampticus 12\%; PPH 2\%; APH 2\%;
ARF 4\%; aspiration pneumonia 2\%; DIC 4\%; cortical venous infarct $2 \%$, HELLP syndrome $6 \%$; postpartum psychosis $2 \%$ and post. Reversible encephalopathy syndrome $2 \%$. A total of $57 \%$ complications were reported by Ndaboine et al. ${ }^{10}$ Similar complications were reported by Bhalerao et al. in which they reported a $69 \%$ complication rate viz. $30.91 \%$ antepartum haemorrhage; 5.45\% ARF; $25.66 \%$ with HELLP syndrome, 5.45\% with DIC, $7.27 \% \mathrm{PPH}$; and pulmonary edema in $1.82 \%$ cases. ${ }^{18}$ A total of 3 deaths $(5.45 \%)$ were reported. Sunita $\mathrm{TH}$ in her study, reported $33 \%$ complications viz. pulmonary edema 2\%; CVA 2\%; ARF 2\%, HELLP syndrome 7\%; APH 2\%; DIC 3\%; ARDS 2; PPH 6\%; aspiration pneumonia $1 \%$; postpartum psychosis $1 \%$; cortical blindness $1 \%$ and mortality $4 \%{ }^{6}$

In the present study, a total of $48(96 \%)$ women were discharged from hospital and 2 women died. Case fatality rate was $4 \%$. In our study, we found a statistically significant difference $(\mathrm{P}=0.0001)$ when patients discharged in healthy state were compared with maternal deaths due to eclampsia. This may be attributed to the high level of care provided at a tertiary care centre.

In our study, $52 \%$ patients were delivered by caesarean section and $48 \%$ by vaginal delivery out of which $29.2 \%$ were instrumental deliveries. Arshad T reported a total of $37.5 \%$ LSCS deliveries; $25 \%$ by forceps; $37.5 \%$ by spontaneous vaginal delivery. ${ }^{19}$ Khanum et al. showed a $25 \%$ caesarean rate; $71 \%$ normal vaginal delivery; and $2 \%$ each of craniotomy and forceps delivery. ${ }^{11}$ Ndaboine et al reported $66.22 \%$ cases of LSCS and $27.03 \%$ of spontaneous vaginal deliveries. ${ }^{10}$

The convulsion to delivery interval in majority of patients was less than 5 hours duration. Sunita TH reported fit to delivery interval in 29 cases with $<6$ hours duration; 52 cases with 6-12 hours; 18 cases with 12-24 hours. ${ }^{6}$ In the present study, convulsion delivery interval was directly proportional to maternal and perinatal mortality. However, increase in maternal mortality with increasing first fit to delivery interval was not found statistically significant. Similar observation has been made by Swain $\mathrm{S}^{20}$ The perinatal mortality was also found to increase when the interval between the first convulsion and the delivery increases. This is probably due to prolonged fetal exposure to intrapartum asphyxia.

In our study, Magnesium sulphate therapy was effective in controlling convulsions in majority (845\%) cases. Rajasri et al. used magnesium sulphate by Prichards regimen in all their patients. ${ }^{21}$ Suman et al. also used $\mathrm{MgSO}_{4}$ in 799 cases and among them 8 patients developed $\mathrm{MgSO}_{4}$ developed toxicity and they were given phenytoin. ${ }^{17}$

There were 14 perinatal mortalities (28\%) in our study of which 4 cases $(8 \%)$ were early neonatal deaths. Prematurity was the main cause of neonatal deaths (75\%). We had 14\% SGA births and $28 \%$ NICU admissions. Sheraz et al. reported $41.6 \%$ perinatal deaths 
with prematurity; $25 \%$ with birth asphyxia; $16.7 \%$ with IUGR and $16.7 \%$ with meconium aspiration. ${ }^{13}$ Bhalerao reported a $25 \%$ perinatal mortality rate. Neonatal mortality was $5.45 \%$. $18.18 \%$ cases were IUD and $27.27 \%$ cases were IUGR. ${ }^{18}$ Sunita TH reported a $92 \%$ live birth rate and $8 \%$ still births. ${ }^{6}$ We observed $48 \%$ preterm births and similar results were reported by Bhalerao et al. as preterm deliveries $42 \%$ and term $58 \%$ deliveries. ${ }^{18}$ In a study by Khanum et al. there were $66 \%$ live births, $21 \%$ still births and $17 \%$ cases of neonatal deaths. ${ }^{11}$ George IO et al. reported neonatal deaths due to birth asphyxia in $33.3 \%$ cases; $22.2 \%$ by respiratory distress syndrome; $22.2 \%$ with prematurity; $16.7 \%$ with sepsis and $5.6 \%$ with jaundice. ${ }^{22}$ Ndaboine et al. also reported $12,2 \%$ stillbirths, $8.5 \%$ early neonatal deaths $79.3 \%$ live births in their study. ${ }^{10}$ High perinatal mortality rate in our study was probably due to low literacy, poor socioeconomic status and lack of antenatal care.

Eclampsia still remains a major problem in developing countries. It is one of the important causes of maternal and perinatal morbidity and mortality due to lack of proper antenatal care, low socio-economic status and lack of education. Early attention and intensive management are essential for improving the maternal and fetal outcome in eclampsia cases. Unless the social and educational status of women is uplifted and obstetric care is brought to the doorstep, no miracle can be expected. A reduction of death of mother and fetus in cases of eclampsia is possible by wider use of magnesium sulphate, timed delivery, proper implementation of emergency obstetric care facilities.

\section{Funding: No funding sources}

Conflict of interest: None declared

Ethical approval: The study was approved by the institutional ethics committee

\section{REFERENCES}

1. Konje JC, Obisesan KA, Odukoya OA. Presentation and management of eclampsia. Int J Gynecol Obstet. 1992;38:31-5.

2. Swain S, Ojha KN. Maternal and perinatal mortality due to eclampsia. Indian Pediatr. 1993;30:771-3.

3. WHO. The WHO application of ICD-10 to deaths during pregnancy, childbirth and the puerperium. In: WHO, eds. ICD-MM. Geneva: WHO; 2013: 13.

4. Cunnigham FG, Leveno KJ, Bloom SI, Hauth JC, Rouse DJ, Spong CY. Eclampsia. In: Cunnigham FG, Leveno KJ, Bloom SI, Hauth JC, Rouse DJ, Spong CY, eds. In: Williams Obstetrics. 23rd ed. New York: McGraw Hill; 2010: 706-756.

5. Varawalla NY, Ghamande S, Kumud MI. A five year analysis of eclampsia. J Obstet Gynaecol India. 1989;39:513-5.
6. Sunita TH, Desai RM. Eclampsia in a teaching hospital: incidence, clinical profile and response to magnesium sulphate by Zuspan's regimen. IOSR J Dent Med Sci. 2013;4:1-5.

7. Sarkar M, Basak S, Mondal SK, Das S, Roy D, Mandal J, et al. Maternal mortality associated with eclampsia in an Indian Medical College: a four year retrospective study. J Med Med Sci. 2013;4:394-8.

8. Yakasai IA, Gaya SA. Maternal and fetal outcome in patients with eclampsia at Murtala Muhammad specialist hospital Kano, Nigeria. Annal Afr Med Soc. 2011;10:305-9.

9. Kaur K, Shrivastav RD, Rahatgaonkar V, Bhosale UT. Study of fetal and maternal outcome in eclampsia. Int $\mathbf{J}$ Recent Trends Sci Technol. 2014;11:42-4.

10. Ndaboine EM, Kuhunrwa A, Rumanyika R, Beatrice $\mathrm{H}$, Massinde AN. Eclamptic and maternal and perinatal outcomes. Afr J Reprod Health. 2012;16:35.

11. Khanum M, Ashraf F, Sahrin H. A clinical study of 100 cases of eclampsia in Rajshahi Medical College Hospital. Trans Analys J. 2004;17:80-3.

12. Nobis PN. Maternal outcome in eclampsia. Asian $\mathbf{J}$ Obstet Gynaecol Pract. 2002;6:25-8.

13. Sheraz S, Boota M, Shahzad S. Eclampsia. Prof Med J. 2006;13:27-31.

14. Sibai BM. Diagnosis, prevention and management of eclampsia. Obstet Gynaecol. 2005;105:402-10.

15. Douglas KA, Redman CW. Eclampsia in United Kingdom. Br Med J. 1994;309:1395-400.

16. Chames MC, Livingston JC, Invester TS, Barton JR, Sibai BM. Late postpartum eclampsia: a preventable disease. Am J Obstet Gynecol. 2002;186:1174-7.

17. Suman G, Somegowda S. Maternal and perinatal outcome in eclampsia in a district hospital. J Obstet Gynaecol India. 2007;57:324-6.

18. Bhalerao A, Kulkarni S, Ghike S, Kawthalkar A, Joshi S, Somalwar S. Eclampsia: maternal and fetal outcome. J South Asia Fed Obstet Gynaecol. 2013;5:19-21.

19. Arshad T. The prevalence of eclampsia and its complications in patients reporting to military hospital Rawalpindi. Pak Armed Forces Med J. 2007;1:1-9.

20. Swain S. Maternal and perinatal mortality due to eclampsia. Indian J Paediatr. 1993;30:771-3.

21. Rajasri G. Yalival, Jaju PB, Vanishree M. Eclampsia and perinatal outcome: a retrospective study in a teaching hospital. J Clin Diagn Res. 2011;5:1056-9.

22. George IO, Jeremiah I. Perinatal outcome of babies delivered to eclamptic mothers: a prospective study from a Nigerian tertiary hospital. Int J Biomed Sci. 2009;5:390-4.

DOI: $10.18203 / 2320-1770 . i j r \operatorname{cog} 20150068$

Cite this article as: Mor S, Sirohiwal D, Hooda R. Eclampsia: maternal and perinatal outcomes in a tertiary care centre. Int J Reprod Contracept Obstet Gynecol 2015;4:653-7. 